\title{
Retirement of interventional cardiologists
}

\section{Đeiti Prvulović*}

General Hospital "Dr. Josip Benčević", Slavonski Brod, Croatia
RECEIVED:

February 2, 2018

ACCEPTED:

February 10, 2018

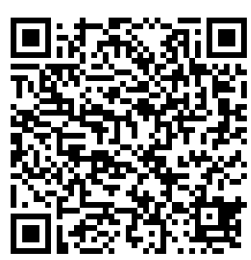

KEYWORDS: retirement age, cognitive impairment, interventional cardiology.

CITATION: Cardiol Croat. 2018;13(1-2):31. | https://doi.org/10.15836/ccar2018.31

*ADDRESS FOR CORRESPONDENCE: Đeiti Prvulović, Opća bolnica "Dr. Josip Benčević", A. Štampara 42, HR-35000 Slavonski Brod, Croatia. / Phone: +385-91-554-7188 / E-mail: deiti.prvulovic@gmail.com

ORCID: Đeiti Prvulović, https://orcid.org/0000-0002-8041-1197

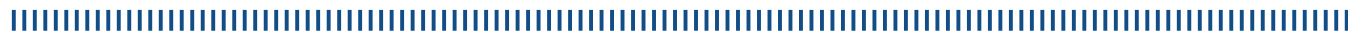

There is no mandated retirement age for physicians in the United States, and physicians 65 and older currently represent 23 percent of physicians in the United States ${ }^{1}$. It is estimated that $5-10 \%$ of people age 65 and older have dementia. ${ }^{2}$ Older physicians have deep knowledge, well-honed interpersonal skills, better judgement than young ones and more balanced perspective. To perform demanding and challenging job of interventional cardiologist, physician must have the physical and mental ability. Health, physical ability, and cognition decline with age, but with significant variability in the cognitive aging process across older adults. ${ }^{2}$ Is there an age limit for interventional cardiologist? Is it everything in the age? If there is physical or cognitive decline, who is going to make an assessment and how to measure it? Who is responsible to act in this situation? What are impediments to stop catheterization laboratory activity? In Croatia there is a lack of experienced interventional cardiologist. Mandatory retirement age is 65. „For many of us, cardiology is not only a career but a lifetime endeavor". ${ }^{3}$ We must think about opportunities of advantages of older colleagues and their possible contribution to the health care environment as potent knowledge and experience resources, in practical work in catheterization laboratory, in advocacy and in education.
LITERATURE IIIIIIIIIIIIIIIIIIIIIIIIIIIIIIIIIIIIIIIIIIIIIIIIIIIIIIIIIIIIIIIIIIIIIIIIIIIIIIIIIIIIIIIIIIIIIIIIIIIIIIIIIIII

1. Smart DR, ed. Physician Characteristics and Distribution in the US, 2015 Edition. Chicago, IL: American Medical Association, 2015.

2. Medcape. Hyer R. Cognitive Impairment in Older Physicians May Be Widespread. Available at: https://www.medscape.com/viewarticle/532007 (1.2.2018).

3. Drag LL, Bieliauskas LA, Langenecker SA, Greenfield LJ. Cognitive functioning, retirement status, and age: results from the Cognitive Changes and Retirement among Senior Surgeons study. J Am Coll Surg. 2010 Sep;211(3):303-7. https://doi.org/10.1016/j.jamcollsurg.2010.05.022 